\title{
EVALUATION OF MODEL PERFORMANCES IN REPRODUCING MEASURES OF THERMAL CONDUCTIVITY OF CRYSTALLINE ROCKS
}

\author{
Diego T. França3 ${ }^{3}$, José A.M. Moreira'1,3, Walter E. Medeiros ${ }^{1,3,4}$, \\ Antônio C. Galindo 2,3 and Fernando A.P.L. Lins' 2,3
}

\begin{abstract}
We evaluate the performances of the Krischer-Esdorn (KE), Hashin-Shtrikman (HS), classic Maxwell (CM), Maxwell-Wiener (MW), and geometric mean (GM) models in reproducing 1,105 measurements of thermal conductivity of crystalline rocks collected in Borborema Province (NE-Brazil). Percent volumes of quartz, K-feldspar, plagioclase, and mafic minerals were also measured. Rock samples were divided into the IOG (igneous and ortho-derived) and MET (metasedimentary) groups. IOG-group (939 samples) covered most the lithologies of the Streckeisen diagram and MET-group (166 samples) covered low-to-medium metamorphic grade lithologies. Reproducing rock conductivities was treated as an inverse problem, where conductivity measurements and constituent mineral volumes are the known quantities while the constituent mineral effective conductivities and model parameters are the unknowns. To identify the model better reproducing the measurements, model performances were compared by using the percentage of number of samples whose estimated conductivities are close to the measured conductivities within the tolerance level of $15 \%$. For all models, the performances are relatively inferior for the MET-group. In the IOG-group, the KE- and HS-model performances are relatively superior. In the MET-group, model performances are very contrasting but the KE-model is again superior. The KE-model thus presents the best performance in reproducing thermal conductivities of crystalline rocks.
\end{abstract}

Keywords: thermal conductivity, rock models, crystalline rocks, Borborema Province.

RESUMO. Avaliamos o desempenho dos modelos Krischer-Esdorn (KE), Hashin-Shtrikman (HS), Maxwell clássico (CM), Maxwell-Wiener (MW), e média geométrica (GM) em reproduzir 1.105 medidas de condutividade térmica de rochas cristalinas da Província Borborema (NE-Brasil). Os percentuais de volume de quartzo, K-feldspato, plagioclásio e minerais máficos foram também medidos. As amostras foram divididas nos grupos IOG (ígneas e ortoderivadas) e MET (metassedimentares). 0 grupo IOG (939 amostras) cobre as litologias principais do diagrama de Streckeisen e 0 grupo MET (166 amostras) contém rochas de baixo a médio graus de metamorfismo. Estimar condutividade de rochas foi tratado como um problema inverso, em que medidas de condutividade e percentuais de volume de minerais são conhecidos enquanto condutividades efetivas de minerais e parâmetros de modelo são incógnitas. 0 desempenho foi avaliado comparando-se a percentagem do número de amostras cujas estimativas de condutividade reproduzem as medidas dentro da tolerância de $15 \%$. Para todos os modelos, os desempenhos são relativamente piores no grupo MET. No grupo IOG, os modelos KE e HS apresentaram os melhores desempenhos. No grupo MET, os desempenhos são contrastantes, mas o modelo KE apresenta melhor desempenho. Assim, o modelo KE apresenta o melhor desempenho em reproduzir as medidas de condutividade térmica de rochas cristalinas.

Palavras-chave: condutividade térmica, modelos de rocha, rochas cristalinas, Província Borborema.

\footnotetext{
1 Universidade Federal do Rio Grande do Norte - UFRN, Centro de Ciências Exatas e da Terra - CCET, Departamento de Geofísica, Campus Universitário - Lagoa Nova, 59078-970 Natal, RN, Brazil - E-mails: moreira@geofisica.ufrn.br; walter@geofisica.ufrn.br

2 Universidade Federal do Rio Grande do Norte - UFRN, Centro de Ciências Exatas e da Terra - CCET, Departamento de Geologia, Campus Universitário - Lagoa Nova, 59078-970 Natal, RN, Brazil - E-mails: galindo@geologia.ufrn.br; flins@geologia.ufrn.br

${ }^{3}$ Universidade Federal do Rio Grande do Norte - UFRN, Centro de Ciências Exatas e da Terra - CCET, Programa de Pós-Graduação em Geodinâmica e Geofísica, Campus Universitário - Lagoa Nova, 59078-970 Natal, RN, Brazil - E-mail: diego_tfranca@hotmail.com

${ }^{4}$ INCT-GP/CNPq - Instituto Nacional de Ciência e Tecnologia em Geofísica do Petróleo.
} 


\section{INTRODUCTION}

Understanding the spatial distribution of heat flow in the Earth's crust is a key element in many important problems, as for example, sedimentary basin evaluation for hydrocarbon exploration (Chapman, 1986), characterization of geothermal reservoirs (Chapman, 1986; Di Sipio et al., 2013), and geological disposal of nuclear waste (Andersson et al., 2000). To estimate the heat flow, it is necessary to measure the geothermal gradient and the rock thermal conductivity of the geologic medium under consideration. Estimations of geothermal gradients are commonly performed based on temperature measurements at depth intervals of 3-10 m (Hamza, 1982; Gomes \& Hamza, 2005; Jessop, 2009) while thermal conductivity measurements are carried out on rock samples with dimensions usually less than one hundredth of this interval. Moreover, due to the facts that rock sampling from boreholes is a relatively expensive operation and rock conductivity measurement is a somewhat time-expensive procedure, relatively few experimental measurements are usually carried out. The process of temperature gradient measurement thus incorporates an averaging process that is lacking in the process of conductivity measurement (Jessop, 1983; Jessop, 2009). To obtain additional estimates of conductivity, a commonly used simplifying approach is to estimate rock thermal conductivities based on models (Clauser \& Huenges, 1995; Schön, 2004), in particular those based on observed or expected rock mineral content (Clauser \& Huenges, 1995). Thus, it is necessary to test the adequacy or performance of thermal conductivity models in reproducing measured values and in evaluating possible errors involved in adopting this simplifying approach.

In this work, we evaluate the performances of Krischer and Esdorn (Schön, 2004), Hashin and Shtrikman (Hashin \& Shtrikman, 1962), classic Maxwell (Schön, 2004), MaxwellWiener (Buntebarth \& Schopper, 1998), and geometric mean (Schön, 2004) models in reproducing representative thermal conductivity values of igneous and metamorphic rocks. We used an extensive data set derived from 1,105 samples of crystalline rocks collected in outcrops of the Borborema Province (Almeida et al., 1981) in Northeastern Brazil. Previous studies (Figueiredo, 2006; Figueiredo et al., 2009; Silva, 2016) discussed the relationships between thermal conductivity, modal composition and geochemistry of larger elements in crystalline silica rocks, notably granite rocks, from Borborema Province (BP), aiming to characterize different magmatic suites of this province. However, as long as we known, no study was done in order to identify the best theoretical models in reproducing the thermal conductivity of crystalline rocks, which is the objective of the present study. To achieve this goal, both thermal conductivity and petrographic modal analysis were done on 1,105 samples of igneous and metamorphic rocks collected in outcrops of the BP. Both conductivity and selected petrographic modal analysis (percent volumes of quartz, K-feldspar, plagioclase, and sum of mafic minerals) were done. We show that most of these simple rock models, in particular the Krischer and Esdorn model, present a quite good performance in reproducing measured values of thermal conductivity of crystalline rocks, particularly for igneous and ortho-derived (or meta-igneous) rocks.

\section{SAMPLED ROCKS}

All rock samples (total of 1,105$)$ used in this study were collected from outcrops of igneous and metamorphic rocks in the northern portion of the BP (Fig. 1). The BP is a major geologic and structural domain located in Northeastern Brazil, limited to the south by the São Francisco craton, to the west by the Parnaíba Basin, and to the north and east by the Atlantic coastal margin. It has a complex Precambrian geologic evolution (Almeida et al., 1981), culminating with the Gondwanaland assembly in the Late Neoproterozoic - Early Paleozoic (Brito Neves \& Cordani, 1991; Trompette, 1994). In the context of Gondwanaland assembly, the BP comprises a Proterozoic fold belt extended between the São Luis - West Africa and São Francisco - Congo/Kasai cratons. It is widely accepted that the BP evolution occurred by a mechanism of terrane collage (e.g. Santos \& Medeiros, 1999; Oliveira, 2008), where large crustal blocks were put together during Meso and Late-Proterozoic events. Major shear zones in E-W and/or NE-SW directions are interpreted as boundaries between terranes, as for example, the Patos, Pernambuco, Jaguaribe-Tatajuba, and Transbrasiliano shear zones indicated in Figure 1.

Selecting and collecting rock samples from outcrops in BP is a relatively easy field operation, since the present semi-arid climate of the region has inhibited formation of thick soil cover and allowed occurrence of large exposures of fresh unweathered basement rocks.

In this study we classify samples of igneous and metamorphic rocks into the two groups of igneous and ortho-derived (or meta-igneous) rocks and metasedimentary rocks. It were collected samples of a large variety of igneous and ortho-derived rocks (Table 1) covering most of the lithologies defined in the Streckeisen diagram (Fig. 2) (Streckeisen, 1976), with higher concentrations in the fields of granite, monzogranite, syenogranite, granodiorite and tonalite. Regarding the metasedimentary rocks, it were sampled representative lithologies (Table 2) usually of low to medium metamorphic grades. 


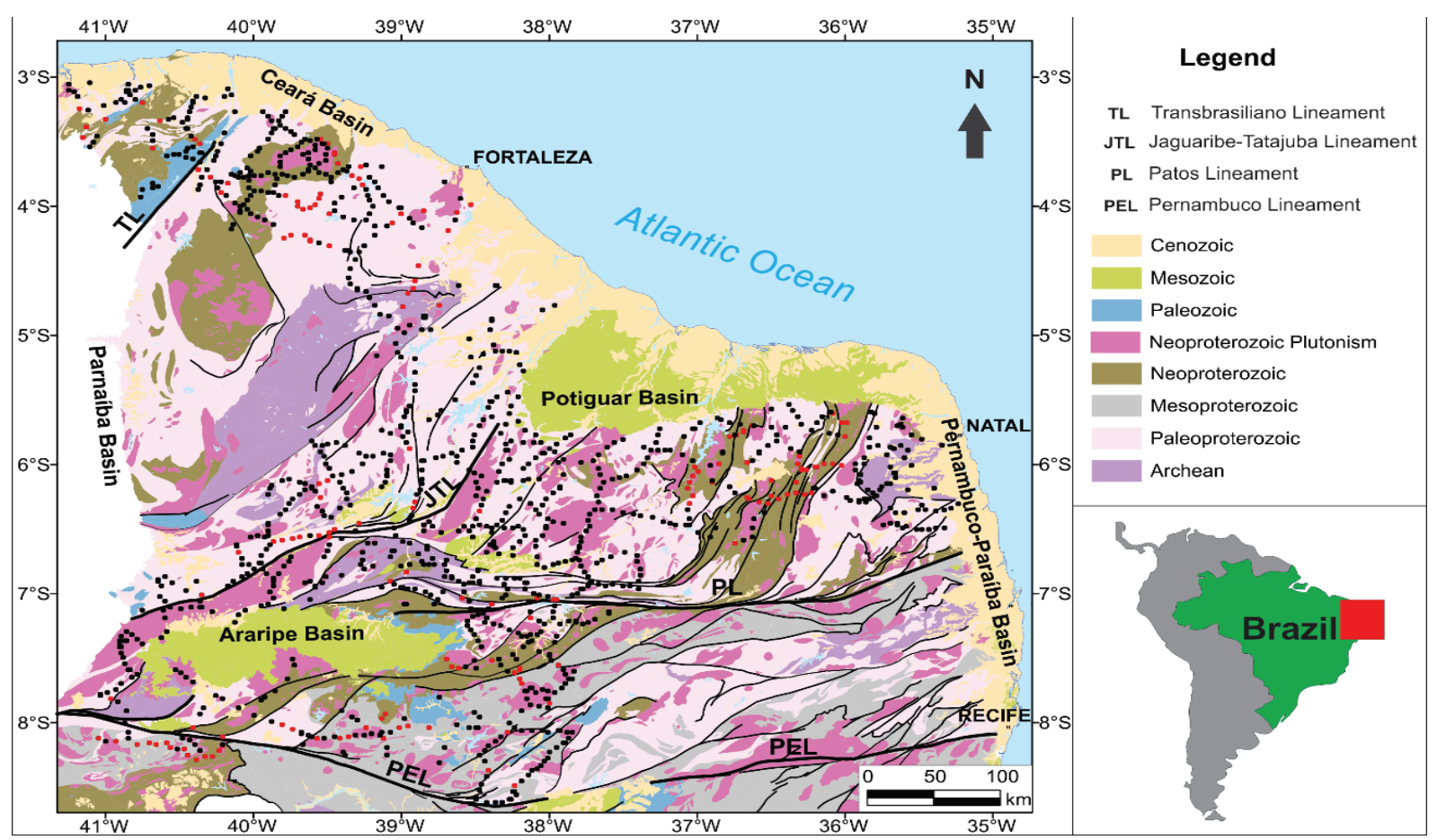

Figure 1-Geologic map of the northern portion of the Borborema Province, Brazil. Locations of sampled rocks are identified as black dots for igneous and ortho-derived rocks and red dots for metasedimentary rocks. Map source: CPRM - Geological Survey of Brazil at http://geobank.sa.cprm.gov.br/.

Table 1 - Sampled lithologies of igneous and ortho-derived rocks according to their classification in the Streckeisen diagram (Streckeisen, 1976).

\begin{tabular}{|c|c|}
\hline Lithology & Number of samples \\
\hline alkali-feldspar granite & 5 \\
alkali-feldspar quartz syenite & 5 \\
alkali-feldspar syenite & 5 \\
granite & 296 \\
granodiorite & 99 \\
monzogranite & 241 \\
quartz diorite & 17 \\
quartz monzodiorite & 11 \\
quartz monzonite & 25 \\
quartz rich granitoid & 5 \\
quartz syenite & 11 \\
quartzolit & 2 \\
syenogranite & 138 \\
tonalite & 79 \\
\hline Total & $\mathbf{9 3 9}$ \\
\hline
\end{tabular}

\section{THERMAL CONDUCTIVITY MEASUREMENTS}

A thermal impedance meter, manufactured by Anter Corp. (model QuicklineTM-30), was used for measurements. This instrument uses two different sensor systems and measures conductivities in the ranges 0.3 to $2.0 \mathrm{Wm}^{-1} \mathrm{~K}^{-1}$ and 2.0 to $6.0 \mathrm{Wm}^{-1} \mathrm{~K}^{-1}$. The principle of operation of this device is based on analysis of transient thermal field produced by a planar heat source (Carslaw \& Jaeger, 1959; Gomes \& Hamza, 2005) in the sample. According to the manufacturer, the mean reproducibility of the measurements is $3 \%$ with accuracy of about $10 \%$ in both ranges. Flat plates with dimensions $11 \mathrm{~cm} \times 11 \mathrm{~cm} \times 3 \mathrm{~cm}$ for length, width, and thickness, respectively, were cut from the rock samples. One of the flat faces was polished to allow a good coupling with the sensor unit of the measuring device. Five measurements (one near each corner and one on the plate centre) were done in each sample, from which values of mean and standard deviation were calculated.

Table 2 - Sampled lithologies of metasedimentary rocks.

\begin{tabular}{|c|c|}
\hline Lithology & Number of samples \\
\hline Marble & 7 \\
Metaconglomerate & 6 \\
Metasandstone & 7 \\
Paragnaiss & 32 \\
Phyllite & 14 \\
Quartzite & 18 \\
Schist & 82 \\
\hline Total & $\mathbf{1 6 6}$ \\
\hline
\end{tabular}




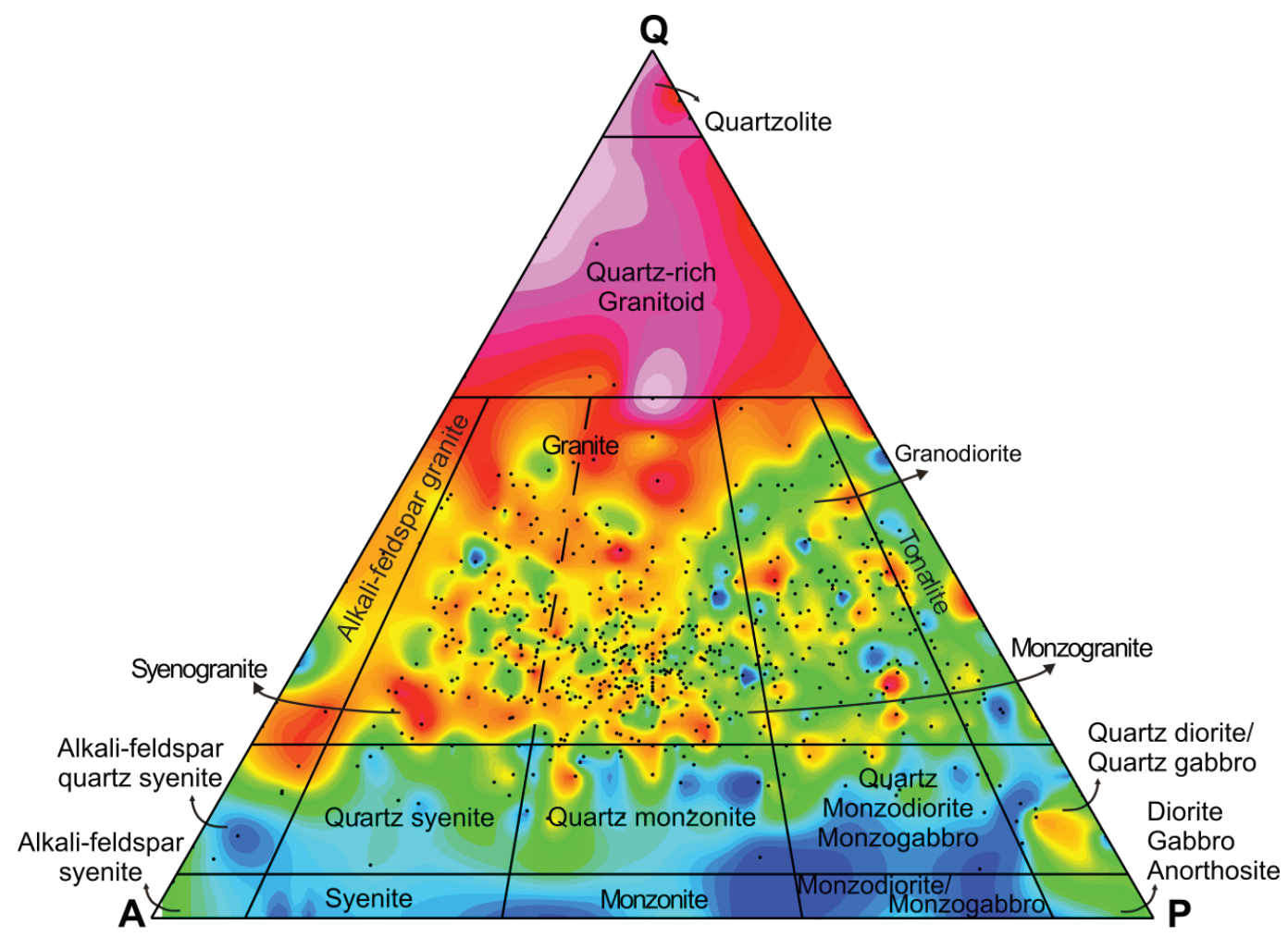

\section{$\begin{array}{lllllllllllll}2.0 & 2.1 & 2.2 & 2.3 & 2.4 & 2.6 & 2.7 & 2.8 & 2.9 & 3.0 & 3.1 & 3.3 & 3.6\end{array}$}

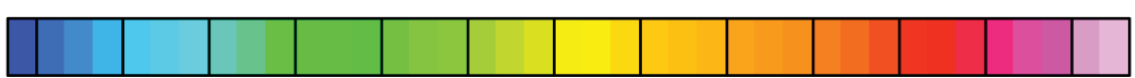

Figure 2 - Streckeisen diagram showing distribution of the 939 samples (black dots) of igneous and ortho-derived rocks and contours of their measured conductivities in $\mathrm{Wm}^{-1} \mathrm{~K}^{-1}$.

Results of conductivity measures (Fig. 3) are in the range 1.0 to $7.0 \mathrm{Wm}^{-1} \mathrm{~K}^{-1}$, with most of them in the range 2.0 to $4.0 \mathrm{Wm}^{-1} \mathrm{~K}^{-1}$. The normalized standard deviation is lower than $10 \%$ for most of the measures (Fig. 3), pointing to relatively good precision in experimental data. For the igneous and orthoderived rocks, the conductivities measures were interpolated as isovalue lines on the Streckeisen diagram (Fig. 2). Observe that the expected broad increase in thermal conductivity with increasing quartz content is clear.

\section{PETROGRAPHIC MODAL ANALYSIS AND GEOCHEMISTRY}

Mineral content modal analyses were carried out for all rock samples using a conventional petrographic microscope and thin polished sections of rocks (with thickness in the range 25 to $30 \mu \mathrm{m})$. The percent volumes of quartz $\left(V_{Q z}\right)$, K-feldspar $\left(V_{K f}\right)$, plagioclase $\left(V_{P l}\right)$, and sum of mafic minerals $\left(V_{M a}\right)$ were estimated by using a computerized version of the classic point count method (Chayes, 1956), being the statistics based on 600 points. In the case of metasedimentary rocks presenting high anisotropy, a visual estimate of the silica percent composition was also done. Data on silica percent weight derived from results of geochemical analyses were also available for a subset of 160 samples of igneous rocks. These can easily be converted to the silica percent volume, given the densities of the silica and of the sample. For quartz volume fraction in the range of 0.05 to 0.4 , there is good correlation between the silica percent volume, given by the geochemistry, and the quartz percent volume, given by the petrographic modal analysis (Fig. 4). We show later that it is possible to estimate the rock conductivity from the silica percent volume using this correlation.

\section{THERMAL CONDUCTIVITY MODELS}

All models considered in this study are based on the volume fraction of the main minerals forming the rocks and on the thermal conductivity of these minerals. It is assumed that the rock is 


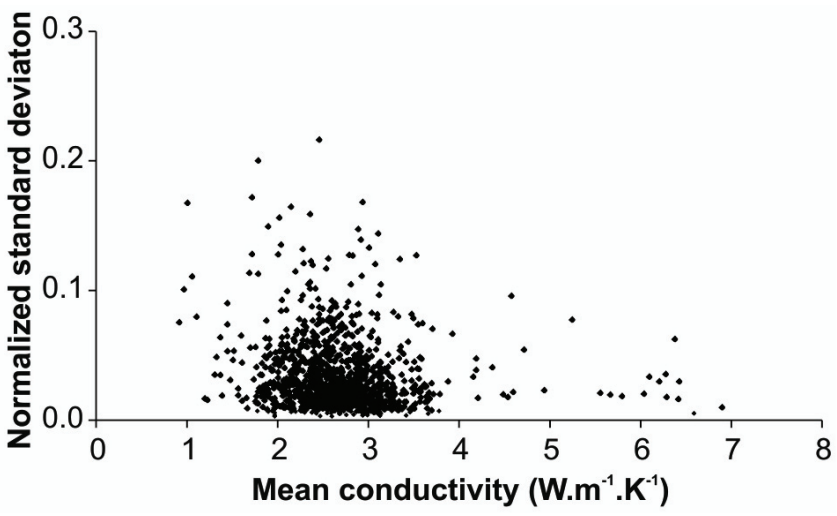

Figure 3 - Quality of the conductivity measures as expressed by mean and normalized (by the mean) standard deviation for each rock sample. There are 1,105 rock samples. To estimate mean and standard deviation of each rock sample five measures of conductivity were used.

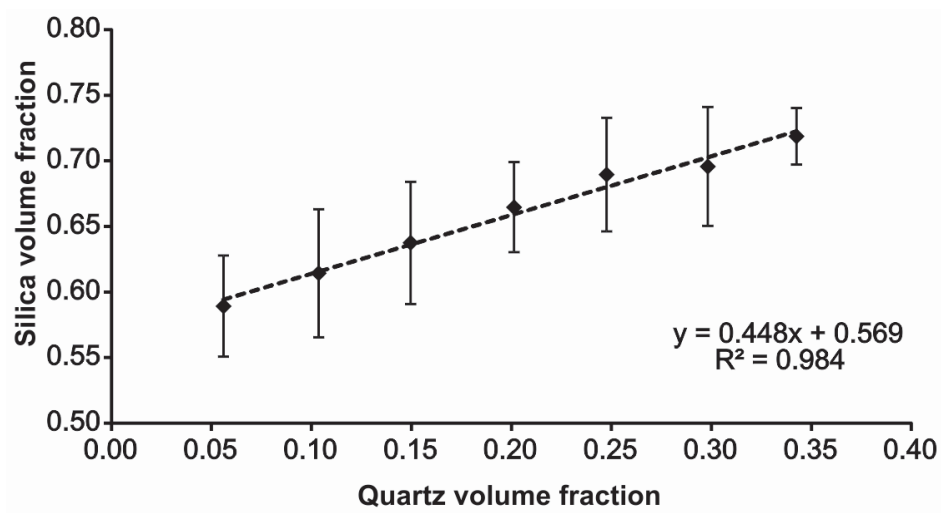

Figure 4 - Correlation between silica percent volume (from results of geochemical analysis) and quartz percent volume (from petrographic modal analysis), for quartz volume fraction in the range 0.05 to 0.4 . The silica volumes were averaged over the corresponding sequential strips (with width of $5 \%$ ) of quartz percent volume.

formed by volume fractions $V_{i}$, of $N$ minerals $(i=1, N)$, each mineral having conductivity $\lambda_{i}$. Commonly, quartz, K-feldspar, plagioclase, and sum of mafic minerals are the main constituents. We considered the models of Krischer and Esdorn (Schön, 2004), Hashin and Shtrikman (Hashin \& Shtrikman, 1962), classic Maxwell (Schön, 2004), Maxwell-Wiener (Buntebarth \& Schopper, 1998) and geometric mean (Schön, 2004). Below is given a brief description of each model.

The Krischer and Esdorn model (KE-model) estimates the conductivity $\lambda^{K E}$ of the rock as

$$
\begin{aligned}
& \lambda^{K E}=\left(\frac{\alpha}{\lambda_{s}}+\frac{1-\alpha}{\lambda_{p}}\right)^{-1}, \\
& \lambda_{s}^{-1}=\sum_{i=1}^{N} V_{i} \cdot \lambda_{i}^{-1}, \\
& \lambda_{p}=\sum_{i=1}^{N} V_{i} \cdot \lambda_{i} .
\end{aligned}
$$

In Eq. (1), $\alpha$ is a parameter that defines in a somewhat empirical way the mineral volume fraction that is connected in series in the rock volume. For this model, $\alpha=0$ and $\alpha=$ 1 correspond to the two end-members of parallel and series cases, when $\lambda^{K E}$ would be equal to $\lambda_{p}$ (Eq. 3) or $\lambda_{s}$ (Eq. 2), respectively.

The Hashin and Shtrickman model (HS-model) estimates a conductivity $\lambda^{H S}$ for the rock with a formula equivalent to Eq. (1) but using a maximum $\left(\lambda_{\max }^{H S}\right)$ and a minimum $\left(\lambda_{\min }^{H S}\right)$ estimates for the rock conductivity instead of $\lambda_{p}$ (Eq. 3) and $\lambda_{s}$ (Eq. 2), respectively. The equations defining the HS-model are

$$
\begin{aligned}
& \lambda^{H S}=\left(\frac{\alpha}{\lambda_{\min }^{H S}}+\frac{1-\alpha}{\lambda_{\max }^{H S}}\right)^{-1}, \\
& \lambda_{\max }^{H S}=\lambda_{\max }+\frac{A_{\max }}{\left(1-a_{\max } A_{\max }\right)}, \\
& \lambda_{\min }^{H S}=\lambda_{\min }+\frac{A_{\min }}{\left(1-a_{\min } A_{\min }\right)},
\end{aligned}
$$




$$
\begin{aligned}
& A_{\max }=\sum_{i=1}^{N} V_{i}\left[\left(\lambda_{i}-\lambda_{\max }\right)^{-1}+a_{\max }\right]^{-1}, \\
& A_{\min }=\sum_{i=1}^{N} V_{i}\left[\left(\lambda_{i}-\lambda_{\min }\right)^{-1}+a_{\min }\right]^{-1}, \\
& \lambda_{\max }=\max \left(\lambda_{i}\right), \lambda_{\min }=\min \left(\lambda_{i}\right), i=1, N, \\
& a_{\max }=\frac{1}{3 \lambda_{\max }}, a_{\min }=\frac{1}{3 \lambda_{\min }} .
\end{aligned}
$$

In the HS-model the rock is assumed to be composed of spheres in mutual contact with a coat covering completely the surfaces of the spheres. Equations (5) and (6) correspond to the cases where the conductivity of the coat is higher or lower, respectively, than the conductivity of the inner sphere.

The classic Maxwell model (CM-model) estimates the rock conductivity $\lambda^{C M}$ based on the assumption that the rock is composed of two phases: a continuous homogeneous medium, the matrix, and randomly distributed isolated spheres, all spheres having the same composition. It is also supposed that the total volume of the spheres is low compared to the matrix volume. In crystalline rocks, the quartz is usually taken as the material composing the spheres and the matrix is the union of all other minerals forming the rock. We define $V_{Q z}$ as the volume fraction of quartz with conductivity $\lambda_{Q z}$. In a similar manner, $\lambda_{M x}$ and $V_{M x}$ are defined as the conductivity and volume fraction of the matrix, respectively. According to Schön (2004), $\lambda^{C M}$ is given by

$$
\begin{gathered}
\lambda^{C M}= \\
\lambda_{M x}\left[\frac{\lambda_{Q z}+2 \lambda_{M x}+2 V_{Q z}\left(\lambda_{Q z}-\lambda_{M x}\right)}{\lambda_{Q z}+2 \lambda_{M x}-V_{Q z}\left(\lambda_{Q z}-\lambda_{M x}\right)}\right] .
\end{gathered}
$$

We considered also in this study the Maxwell-Wiener model (MW-model) that is the generalization done by Wiener (Buntebarth \& Schopper, 1998) of the CM-model. The MW-model was by us parameterized as

$$
\begin{gathered}
\lambda^{M W}= \\
\lambda_{M x}\left[\frac{P^{-1} \lambda_{Q z}+2 P \lambda_{M x}+2 P V_{Q z}\left(\lambda_{Q z}-\lambda_{M x}\right)}{P^{-1} \lambda_{Q z}+2 P \lambda_{M x}-P^{-1} V_{Q z}\left(\lambda_{Q z}-\lambda_{M x}\right)}\right],
\end{gathered}
$$

where $P$ is a parameter defined in the interval $(0, \infty)$ and $\lambda^{M W}$ varies continuously with $P$. When $P=1$, Eq. (12) reduces to Eq. (11). Moreover, when $P \ll 1$ (say, 0.1 ) and $P \gg 1$ (say, 10), Eq. (12) reduces to the same two end-members of series and parallel models, respectively associated with $\alpha=0$ and $\alpha=1$ in Eq. (1), but now considering the rock as being composed with just two phases (the matrix and the spheres).

Finally, we used also the geometric mean model (GM-model) where the rock conductivity is estimated by

$$
\lambda^{G M}=\prod_{i=1}^{N} \lambda_{i}^{V_{i}}
$$

In cases where the matrix is composed of quartz, K-feldspar, plagioclase and mafic minerals, the KE and HS-models use five parameters $\left(\lambda_{Q z}, \lambda_{K f}, \lambda_{P l}, \lambda_{M a}\right.$, and $\left.\alpha\right)$ while the GMmodels use four parameters $\left(\lambda^{Q z}, \lambda^{K f}, \lambda^{P l}\right.$, and $\left.\lambda^{M a}\right)$. On the other hand, the CM and MW-models use two ( $\lambda_{Q z}$ and $\left.\lambda_{M x}\right)$ or three parameters $\left(\lambda_{Q z}, \lambda_{M x}\right.$ and $\left.P\right)$, respectively. In general, the larger is the number of model parameters, the greater the flexibility of the model.

\section{MODELLING APPROACH}

The above-described models do not take into account the influence of any other characteristic of the rock except its main mineral content and associated thermal conductivities. However, there are other possible factors that influence the effective values of the mineral conductivities as, for example, the degree of anisotropy. Thus, to obtain meaningful results using the described simple models, we adopted the approach of reproducing a large number of measurements of rock conductivity using just one model (with its associated parameters) and one set of effective conductivities for the constituent minerals. In other words, we treat the task of reproducing the measured values of rock conductivity as an inverse problem where values of rock conductivity and the volume fractions of the constituent minerals are considered known quantities while the effective conductivities of the constituent minerals and the model parameters are considered unknown quantities. So, the central idea is to identify the model (and its associated estimates of effective mineral conductivities and parameters) that better accounts for the measured values of rock conductivity.

To show that the inversion approach is feasible, we calculated rock conductivities using the simple series and parallel models (Eqs. 2 and 3, respectively), in each case varying the quartz conductivity in the range 3.0 to $12.0 \mathrm{Wm}^{-1} \mathrm{~K}^{-1}$ and keeping constant the other three mineral conductivities (Clauser \& Huenges, 1995) as 3.1, 2.2, and $2.0 \mathrm{Wm}^{-1} \mathrm{~K}^{-1}$, for K-feldspar, plagioclase, and sum of mafic minerals, respectively. Figure 5 shows the results as family of curves, each family member being identified by the assumed value for the quartz conductivity. Superposed on the family curves, are the measured values of rock conductivity. Both cases (association in series in Fig. 5A and in parallel in Fig. 5B) 
show that a single curve of the family can honor all measures, within the error bar, when the quartz volume is lower than $80 \%$. However, note that the effective quartz conductivity must be in the lower portion of its range in both cases, requiring even lower values in the parallel case. Moreover, by using the parallel case it is clearly more difficulty to honor all measures than in the series case. Nonetheless these limitations, this simple exercise, using just one parameter based on the dominant effect of the quartz content, evidences that a model with four or five parameters certainly will reproduce adequately rock conductivities.

Given the thermal conductivity measures for $\mathrm{N}$ rock samples and the respective volume fractions of the main constituent minerals, the inverse problem, for a given model (for example, the $\mathrm{KE}-\mathrm{model})$, consists in estimating the effective mineral conductivities and parameter values that minimize a misfit functional between all measured and modeled values of conductivity. In this study we use both classic misfit functionals (Menke, 1984) in the $\ell_{1}$ and $\ell_{2}$ (least-squares) norms, respectively given below for the KE-model as:

$$
\begin{aligned}
& \Omega_{1}\left(\lambda_{Q z}, \lambda_{K f}, \lambda_{P l}, \lambda_{M a}, \alpha\right) \\
= & \sum_{j=1}^{N}\left|\lambda_{j}^{\exp }-\lambda_{j}^{K E}\left(\lambda_{Q z}, \lambda_{K f}, \lambda_{P l}, \lambda_{M a}, \alpha\right)\right|, \\
& \Omega_{2}\left(\lambda_{Q z}, \lambda_{K f}, \lambda_{P l}, \lambda_{M a}, \alpha\right) \\
= & \sum_{j=1}^{N}\left|\lambda_{j}^{\exp }-\lambda_{j}^{K E}\left(\lambda_{Q z}, \lambda_{K f}, \lambda_{P l}, \lambda_{M a}, \alpha\right)\right|^{2} .
\end{aligned}
$$

Analogous problems can also be formulated for the other models. Thus, for each one of the two described rock groups (one with the igneous and ortho-derived rocks and the other with the metasedimentary rocks), an inverse problem is solved for each pair of model and fitting criterium. As a result, twenty inversion problems are then solved.

Because the functionals $\Omega_{1}$ and $\Omega_{2}$ (Eqs. 14 and 15) are non-linear and there are points in the search-space where $\Omega_{1}$ might not have gradient in relation to the unknowns, we solved all inverse problems by using an optimization approach based on a gradientless search method (Richardson \& Kuester, 1973) to find the minimum (or one of the minima) of the inverse problems. Three additional reasons justify the use of Richardson \& Kuester (1973) method: (1) the number of unknowns are always small (between 2 and 5), (2) its implementation is simple, and (3) it furnishes, besides the best solution, a set of quasi-solutions (satisfying some stopping criteria), from which standard deviations of the inversion problems solutions can also be calculated.
Details about this optimization method can be found for example in Richardson \& Kuester (1973) and Santana et al. (2012).

\section{RESULTS}

\section{Estimated effective conductivities of the minerals}

The twenty solutions for the effective mineral conductivities and parameter values are given in Tables 3 and 4. All estimated conductivity values are within the accepted ranges, except for the GM-model estimates of the effective conductivity of the mafic minerals. No matter of the used norm, the obtained solutions are near the end-member cases: the series case both in the KE-model $(\alpha \approx 1)$ and in the MW-model $(P \approx 0)$ or the minimum in the HS-model $(\alpha \approx 1)$. About the norm type, there is a tendency that the effective values of conductivity for the quartz, estimated with the $\ell_{1}$ norm, be lower that the values estimated with the $\ell_{2}$ norm. This tendency is due to the known fact that the $\ell_{1}$ norm attributes low weight values for the outliers (Menke, 1984), in this case, a relatively small number of rock samples with high values of measured conductivities.

Table 3 - Solutions for the KE, HS, and GM-models. The line separates the results for igneous and ortho-derived rocks, above, from the results for metasedimentary rocks, below. Conductivities are expressed in $\mathrm{Wm}^{-1} \mathrm{~K}^{-1}$.

\begin{tabular}{|c|c|c|c|c|c|c|}
\hline Model & Norm & $\lambda_{Q z}$ & $\lambda_{K f}$ & $\lambda_{P l}$ & $\lambda_{M a}$ & $\alpha$ \\
\hline $\mathrm{KE}$ & $\ell_{1}$ & 6.87 & 2.54 & 2.04 & 1.88 & 0.98 \\
$\mathrm{HS}$ & $\ell_{1}$ & 4.51 & 2.70 & 2.08 & 1.77 & 0.69 \\
$\mathrm{GM}$ & $\ell_{1}$ & 4.34 & 2.74 & 2.09 & 1.77 & - \\
$\mathrm{KE}$ & $\ell_{2}$ & 7.45 & 2.46 & 2.00 & 1.98 & 1.00 \\
$\mathrm{HS}$ & $\ell_{2}$ & 6.12 & 2.39 & 1.87 & 1.86 & 1.00 \\
$\mathrm{GM}$ & $\ell_{2}$ & 5.60 & 2.38 & 1.85 & 1.89 & - \\
\hline $\mathrm{KE}$ & $\ell_{1}$ & 6.71 & 2.72 & 2.80 & 1.36 & 1.00 \\
$\mathrm{HS}$ & $\ell_{1}$ & 5.96 & 2.54 & 2.89 & 1.13 & 1.00 \\
$\mathrm{GM}$ & $\ell_{1}$ & 5.49 & 2.38 & 3.06 & 0.97 & - \\
$\mathrm{KE}$ & $\ell_{2}$ & 6.80 & 2.66 & 3.01 & 1.37 & 1.00 \\
$\mathrm{HS}$ & $\ell_{2}$ & 6.42 & 2.62 & 2.97 & 1.07 & 1.00 \\
$\mathrm{GM}$ & $\ell_{2}$ & 5.95 & 2.57 & 2.86 & 0.89 & - \\
\hline
\end{tabular}

Table 4 - Solutions for the CM and MW-models. The line separates the results for igneous and ortho-derived rocks, above, from the results for metasedimentary rocks, below. Conductivities are expressed in $\mathrm{Wm}^{-1} \mathrm{~K}^{-1}$.

\begin{tabular}{|c|c|c|c|c|}
\hline Model & Norm & $\lambda_{Q z}$ & $\lambda_{M x}$ & $P$ \\
\hline CM & $\ell_{1}$ & 4.79 & 2.08 & 1.00 \\
MW & $\ell_{1}$ & 7.14 & 2.13 & 0.02 \\
CM & $\ell_{2}$ & 5.66 & 1.99 & 1.00 \\
MW & $\ell_{2}$ & 7.47 & 2.14 & 0.01 \\
\hline CM & $\ell_{1}$ & 4.96 & 1.61 & 1.00 \\
MW & $\ell_{1}$ & 5.78 & 1.78 & 0.01 \\
CM & $\ell_{2}$ & 5.59 & 1.41 & 1.00 \\
MW & $\ell_{2}$ & 5.29 & 1.72 & 0.01 \\
\hline
\end{tabular}



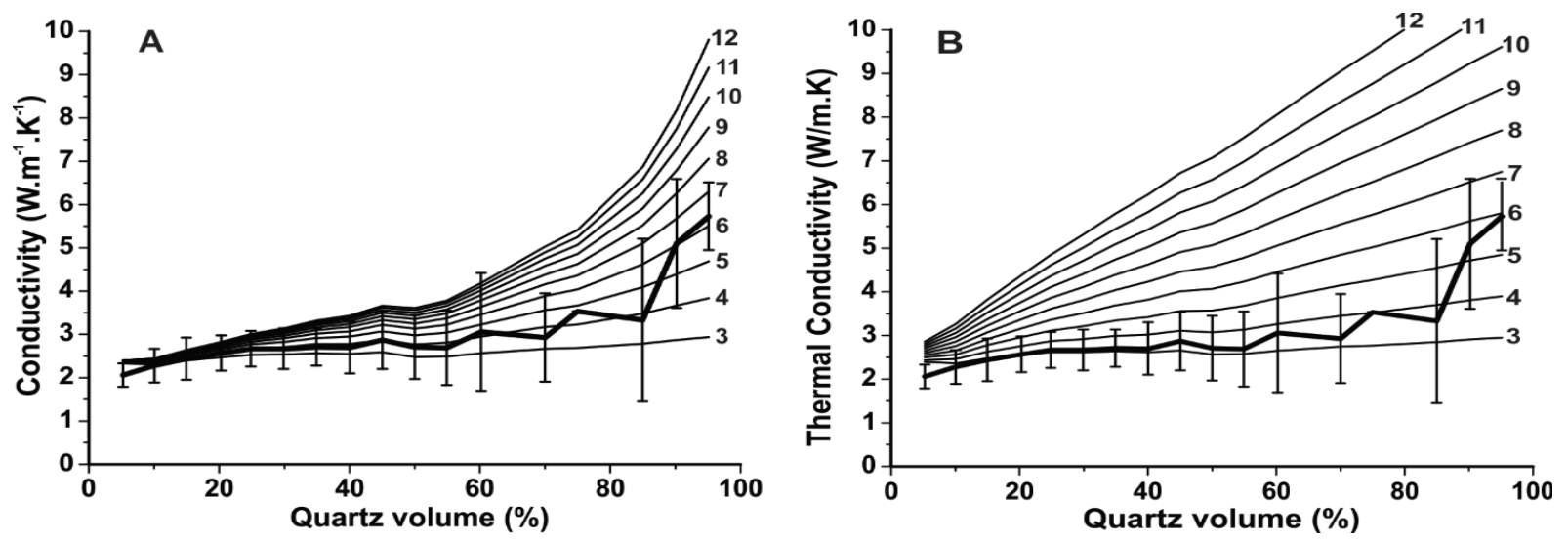

Figure $\mathbf{5}$ - Rock conductivity as function of the percent quartz volume. Thin black lines comprise a family of curves giving rock conductivity estimates for the series (A) and parallel (B) models (Eqs. 2 and 3, respectively). In both cases, the quartz conductivity varies in the range 3.0 to $12.0 \mathrm{Wm}^{-1} \mathrm{~K}^{-1}$, as indicated in the curves. The other three mineral conductivities are kept constant (see text for details). Thick black lines show measured values of rock conductivity. The bars identify the limits of \pm one standard deviation centered in the mean value. Both measured and estimated conductivities are averaged over sequential intervals of $5 \%$ in quartz volume.

\section{Model performances}

Table 5 shows the misfit cumulative frequency distribution $\Gamma$ as function of tolerance. For each rock sample $j$, the relative error $\varepsilon_{j}$ in estimating the measured conductivity $\lambda_{j}^{\exp }$ is given by

$$
\varepsilon_{j}=100 \cdot \frac{\left|\lambda_{j}^{M O D}-\lambda_{j}^{\exp }\right|}{\lambda_{j}^{\exp }},
$$

where $\lambda_{j}^{M O D}$ identifies generically the estimated conductivity with a certain model. So $\Gamma$ gives the percentage of number of rock samples, where the difference between estimated and measured values are within a given tolerance $\tau$ (that is, $\varepsilon_{j} \leq \tau$ ). Because the accuracy of the conductivity measurements is about $10 \%$, and there is an intrinsic inaccuracy in the modal analyses, we select the tolerance of $15 \%$ to identify the best solutions.

For igneous and ortho-derived rocks, model performances are very similar $(\Gamma \approx 70 \%)$, except for the GM-model that presented relatively lower values $(51 \%<\Gamma<65 \%)$. The $\Gamma$ values of KE and HS-models were slightly higher than the values for the $\mathrm{CM}$ and MW-models ( $\Gamma \approx 67 \%$ ). This is a somewhat surprising result because the $\mathrm{KE}$ and $\mathrm{HS}$-models have 5 parameters while the CM-model has just 2 parameters. This result is a consequence of the well-known fact (Schön, 2004) that the quartz content is the dominant factor in determining the conductivity of rocks. Moreover, for the MW-model, the solution is in practice the series association of the quartz content. The fact that the estimates of effective quartz conductivity are in the lower portion of its interval (Tables 3 and 4) and the good performance of the series model corroborates the results shown in Figure 5. On the other hand, the fact the GM-model presented a relatively poor performance, even using four parameters, shows that - at least in this case - it does not simulates properly the rock structure.

Table $\mathbf{5}$ - Performances of the models as measured by $\Gamma$ that is equal to the percentage of rock samples for which the difference between estimated and measured conductivities are within a given tolerance $\tau$. The line separates the results for igneous and ortho-derived rocks (upper panel) from the results for metasedimentary rocks (lower panel).

\begin{tabular}{|c|c|c|c|c|}
\hline Model & Norm & $\tau=10 \%$ & $\tau=15 \%$ & $\tau=20 \%$ \\
\hline $\mathrm{KE}$ & $\ell_{1}$ & 49.7 & 69.5 & 81.0 \\
$\mathrm{HS}$ & $\ell_{1}$ & 51.4 & 70.0 & 81.3 \\
$\mathrm{CM}$ & $\ell_{1}$ & 49.0 & 66.6 & 80.2 \\
$\mathrm{MW}$ & $\ell_{1}$ & 48.7 & 65.9 & 80.1 \\
$\mathrm{GM}$ & $\ell_{1}$ & 49.1 & 64.6 & 76.5 \\
$\mathrm{KE}$ & $\ell_{2}$ & 50.3 & 70.1 & 81.0 \\
$\mathrm{HS}$ & $\ell_{2}$ & 48.9 & 69.1 & 80.8 \\
$\mathrm{CM}$ & $\ell_{2}$ & 47.9 & 67.0 & 78.9 \\
$\mathrm{MW}$ & $\ell_{2}$ & 47.7 & 67.3 & 79.8 \\
$\mathrm{GM}$ & $\ell_{2}$ & 37.2 & 51.2 & 65.2 \\
\hline $\mathrm{KE}$ & $\ell_{1}$ & 48.5 & 65.2 & 76.8 \\
$\mathrm{HS}$ & $\ell_{1}$ & 36.1 & 53.6 & 65.7 \\
$\mathrm{CM}$ & $\ell_{1}$ & 25.3 & 42.2 & 51.2 \\
$\mathrm{MW}$ & $\ell_{1}$ & 27.7 & 40.4 & 53.0 \\
$\mathrm{GM}$ & $\ell_{1}$ & 27.8 & 42.0 & 54.2 \\
$\mathrm{KE}$ & $\ell_{2}$ & 46.8 & 64.2 & 75.9 \\
$\mathrm{HS}$ & $\ell_{2}$ & 37.3 & 53.0 & 65.1 \\
$\mathrm{CM}$ & $\ell_{2}$ & 21.1 & 33.7 & 51.8 \\
$\mathrm{MW}$ & $\ell_{2}$ & 30.1 & 39.2 & 54.8 \\
$\mathrm{GM}$ & $\ell_{2}$ & 22.5 & 35.1 & 47.6 \\
\hline
\end{tabular}

For metasedimentary rocks, model performances were found to be quite contrasting. In general, the $\Gamma$ values are lower for all 


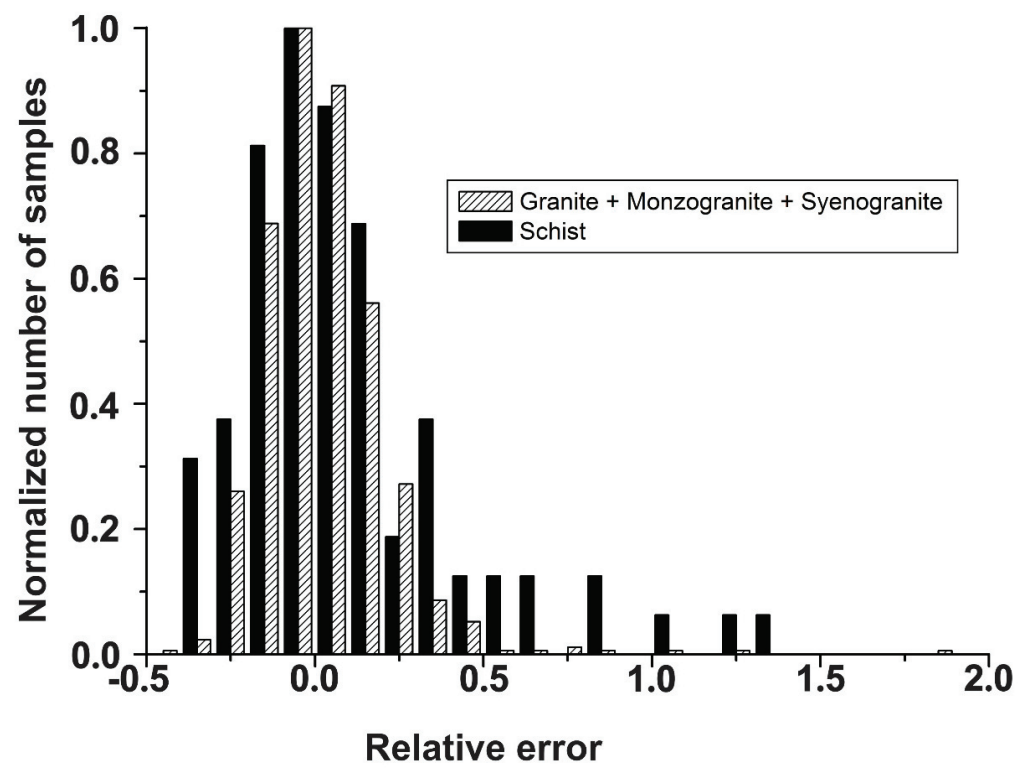

Figure $\mathbf{6}$ - Histograms of normalized number of samples against relative error. For each rock sample of the identified lithologies, the error is the difference between the rock conductivity estimate, calculated with the KE-model $\left(\ell_{2}\right.$ norm), and the rock conductivity measure, normalized by the latter one. The number of samples is normalized by the mode value in each group of lithologies (16 for schist and 173 for the set of granite, monzogranite, and syenogranite).

models than in the case of igneous and ortho-derived rocks. One of the main reasons for this result is the fact that the metasedimentary rocks ( $50 \%$ of them are schist) are richer in platy-minerals than igneous and ortho-derived rocks. In the presence of platyminerals, it is more difficult to obtain a good thermal contact between the sample and the sensor system. Moreover, one of the most common platy-minerals - the biotite - presents a very high degree of anisotropy in conductivity. In this case, just the mineral volume fractions are not sufficient to account for the conductivity variations. Indeed, Figure 6 shows that high discrepancies between measured and estimated conductivities (given by $\varepsilon_{j}$ in Eq. 16, in this case without taking the modulus operation) are most common in schist than in granite.

For metasedimentary rocks, the KE-model is quite superior ( $\Gamma \approx 65 \%)$ than the HS-model $(\Gamma \approx 53 \%)$. On the other hand, the performances of the CM $(\Gamma<42 \%)$, MW $(\Gamma<40 \%)$, and GM $(\Gamma<42 \%)$ models were quite inferior than the KE-model. Certainly, this is a consequence of the higher number of parameters defining the KE-model, except for the GM-model. Again, the fact that the GM-model (with 4 parameters) presented a relatively poor performance is additional evidence that it does not account properly for the thermal conductivity structure of crystalline rocks.

To attest the robustness and stability of the above-described $\Gamma$ values, we used the following approach. For each inversion case, the set of rock samples was randomly sorted in order to construct twenty subsets with just $90 \%$ of the full set. Using the subsets, mean and variance of the $\Gamma$ values were estimated and, as a result, we obtained that the maximum variations in the $\Gamma$ values were lower than $1 \%$ in all inversion cases.

By comparing $\Gamma$ values (Table 5), we identify the KE-model $\left(\ell_{2}\right.$ norm) as the best model for both rock groups. Figure 7 shows the Streckeisen diagram superposed now with the contours of the conductivity values calculated with the KE-model ( $\ell_{2}$ norm) for all samples of igneous and ortho-derived rocks. Comparing Figures 2 and 7 we attest that the reproduction of the conductivity measures is quite good.

Figure 7 can be used as an abacus for gross estimates of thermal conductivity of igneous and ortho-derived rocks that may be of value, for example, for gross estimates of thermal conductivity of rock samples for use in civil engineering.

We identified two main reasons for the cases where the models presented poor performances. One reason, already discussed, is associated to the presence of platy-minerals in the rock. The other reason is the fact that both very low and very high values of rock conductivity are poorly explained by the used models, even for the model presenting the best performance (KE-model, $\ell_{2}$ norm), as shown in Figure 8 . This fact can also be recognized in Figure 5 where it is shown that, in both series and parallel models, one cannot identify a single member of the family curves explaining simultaneously both the very low and very high rock conductivity measures. 


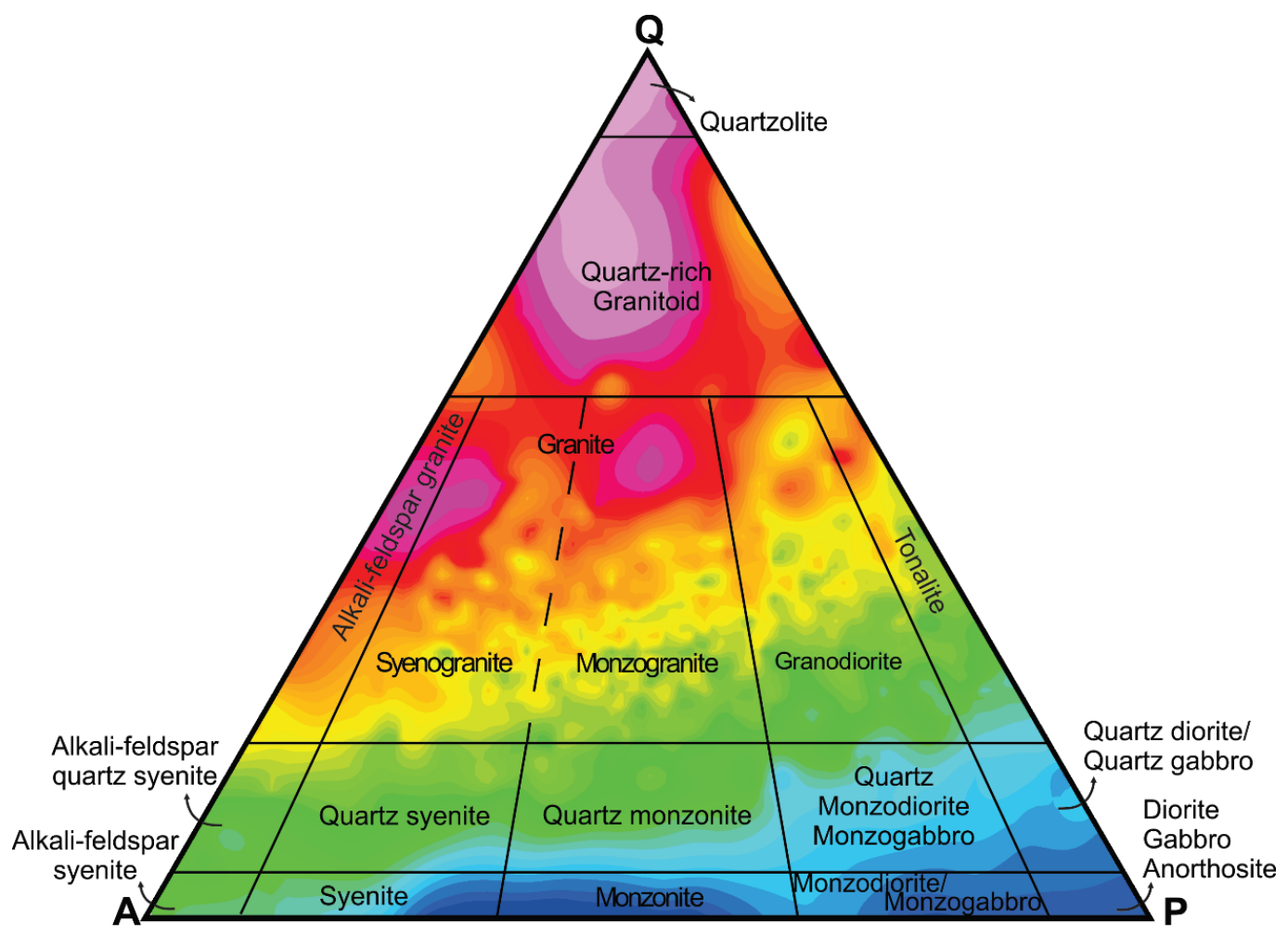

\section{$\begin{array}{lllllllllllll}2.0 & 2.1 & 2.2 & 2.3 & 2.4 & 2.6 & 2.7 & 2.8 & 2.9 & 3.0 & 3.1 & 3.3 & 3.6\end{array}$}

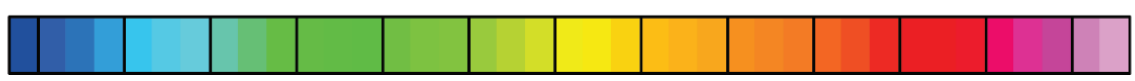

Figure 7 - Streckeisen diagram with superposed contours of estimated rock conductivities calculated with the best performance model (KE-model, $\ell_{2}$ norm). Conductivities are given in $\mathrm{Wm}^{-1} \mathrm{~K}^{-1}$.

\section{Estimating effective conductivity with the silica content}

We showed previously that there is good correlation between the silica percent volume, given by the geochemistry, and the quartz percent volume, given by the petrographic modal analysis (Fig. 4). From this correlation, we can estimate the percent quartz volume that would be given by the modal analysis. The percent matrix volume is the complement to 1.0. Now, using these values and the four sets of estimated effective conductivities for the models with just two phases (Table 4) (CM and MW-models), we obtain rock conductivity estimates shown in Figure 9 against the measures of rock conductivity. There is good correlation between estimated and measured conductivities. In particular, by using the models - with just two parameters - showing the best performances (CM and MW-models, $\ell_{2}$ norm; see Table 5), the estimates of conductivity are contained in the interval of the mean \pm one standard deviation of the measured conductivity (Fig. 10).

\section{Sensibility of the estimated effective conductivities and model parameters}

It is necessary to ascertain if the inversion problems are wellposed problems (Tikhonov \& Arsenin, 1977), that is, if the solutions are stable to small perturbations both in the sample conductivity measures and in the mineral volume fractions. As pointed out before, the used optimization method for solving the inversion problems furnishes, besides the best solution, a set of quasisolutions. Standard deviations of the estimated conductivities (not shown) calculated with these set of quasi-solutions are very small, being lower than $0.04 \mathrm{Wm}^{-1} \mathrm{~K}^{-1}$ for all cases, except for just one case where it was equal to $0.12 \mathrm{Wm}^{-1} \mathrm{~K}^{-1}$ (KE-model, $\ell_{1}$ norm, quartz conductivity, igneous and ortho-derived rocks). The same behavior was observed for the estimates of the parameters associated with the KE, HS and MW-models. These facts evidence that all twenty solutions are stable for small perturbations in the rock conductivity measures. 


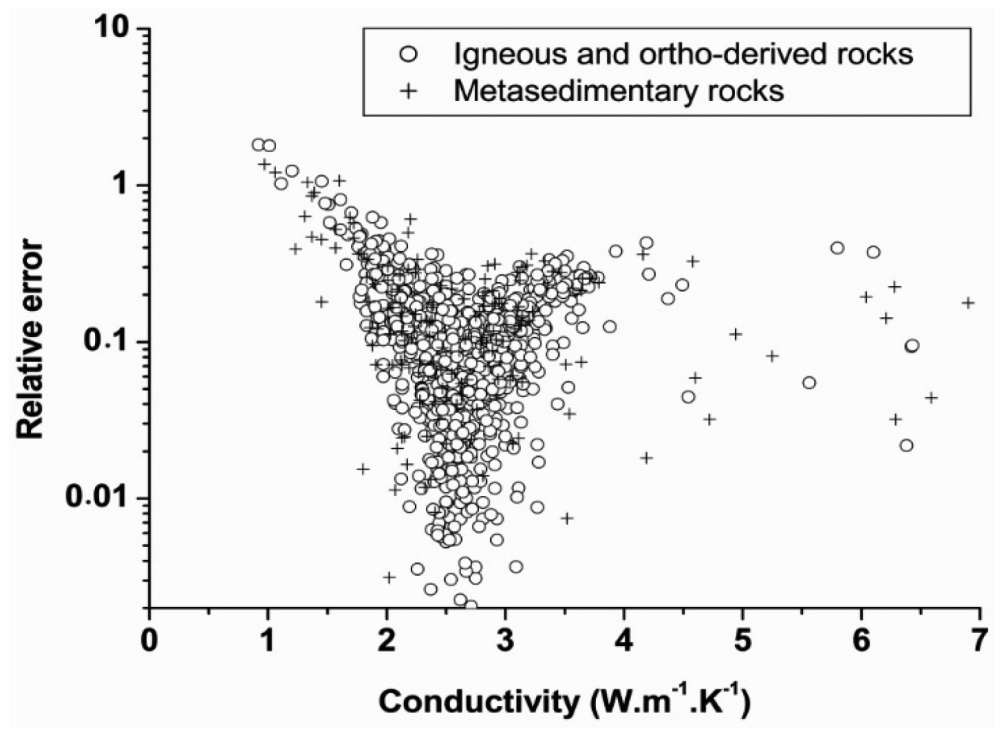

Figure 8 - Relative error (in log scale) in model fits against measured values of rock conductivity. For each rock sample, the error was calculated with Eq. (16) using the KE-model $\left(\ell_{2}\right.$ norm).

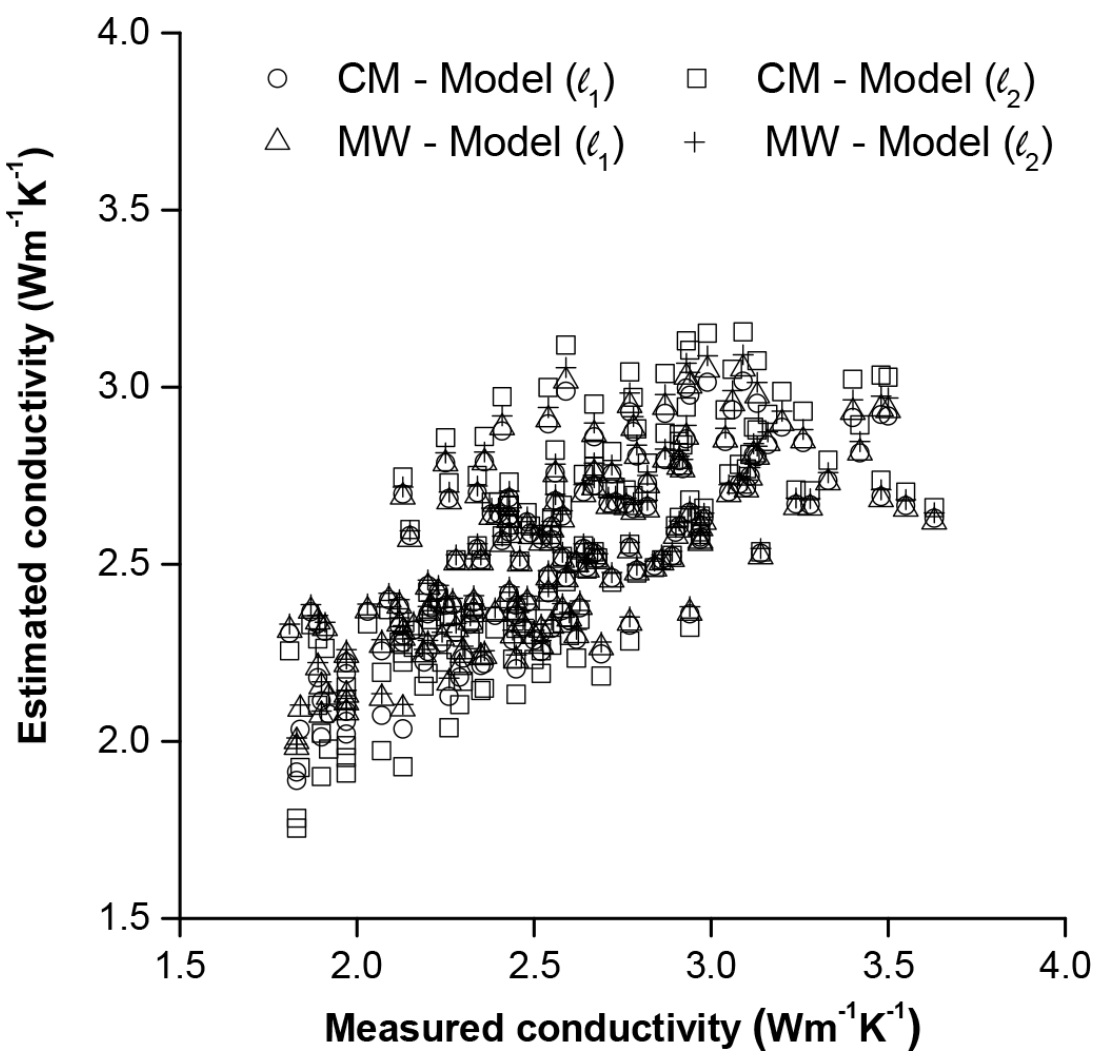

Figure 9 - Estimated rock conductivities, associated with the silica percent volumes, against measured conductivities. It were used 160 samples of igneous rocks for which geochemical analyses are available. Percent quartz volumes are estimated from the silica percent volumes using the correlation shown in Figure 4. Then, percent quartz volumes (and respective complementary percent matrix volumes) are used to estimate the rock conductivities with the four sets of effective conductivities (Table 4) obtained for the models with just two phases (CM and MW-models), for $\ell_{1}$ and $\ell_{2}$ norms. 


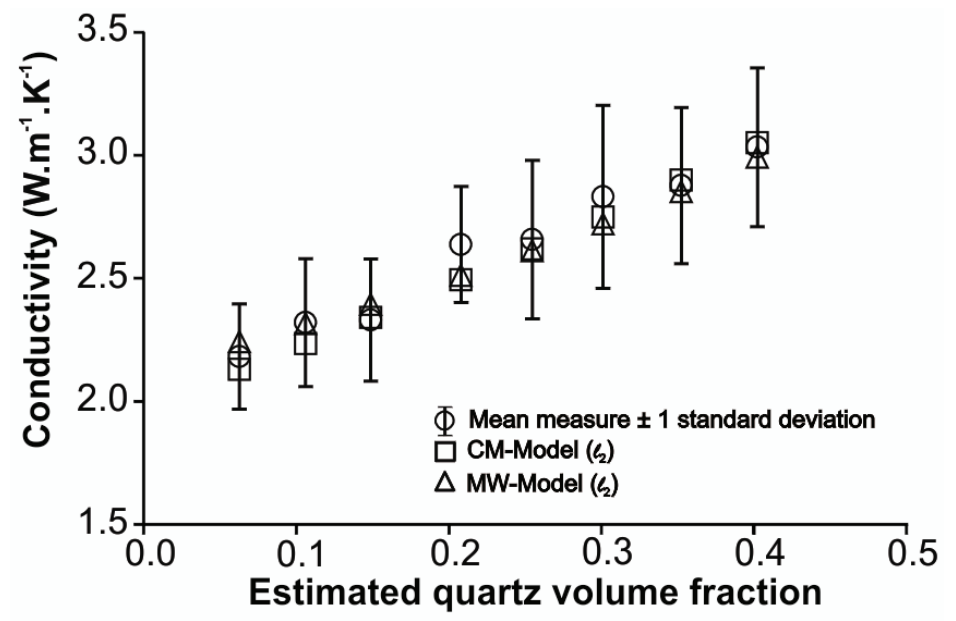

Figure 10 - Rock conductivity against quartz volume fraction. It were used 160 samples of igneous rocks for which geochemical analyses are available. The estimated rock conductivities associated with the silica percent volumes (triangles and squares) are in all cases located within the error bars associated with the rock conductivity measures.

Regarding the sensibility to perturbations in the mineral volume fractions, tests were carried out for the quartz content variation. We added perturbations to the percent quartz volumes (obtained in the modal analyses) by using pseudo-random numbers generated with a zero-mean Gaussian distribution and a given standard deviation $\sigma$ (Press et al., 1996). $\sigma$ was varied in the range $1 \%$ to $5 \%$. In each sample, after the percent quartz volume was perturbed (the perturbation being either positive or negative), the percent volumes of the other minerals were adjusted so that the sum of percent volumes remained equal to 100. It was observed that all solutions are stable to these perturbations, showing however a higher sensibility than perturbations in the sample conductivity measures. As example, we show in Figure 11, for igneous and ortho-derived rocks, and in Figure 12, for metasedimentary rocks, the results for both KE and HS-models ( $\ell_{2}$ norm), which are the models presenting the best performances (Table 5) for both rock groups. These figures show a monotonic behavior for all perturbations in the estimated effective mineral conductivities with increasing $\sigma$, decreasing for the quartz case and increasing for all other minerals. To see that these results are meaningful, we obtained analytical solutions in the $\ell_{2}$ norm, for the simple case of just two phases (quartz and matrix) arranged in series. The analytical solutions are superposed in Figures 11 and 12 confirming the numerical results.

\section{CONCLUSIONS}

Simple models based on the mineral content can explain satisfactorily the thermal conductivity variations of igneous, ortho- derived and metasedimentary rocks. Among the five tested models, the KE-model presented the best performances for the crystalline rocks. The adequacy of the KE-model is good enough to allow one to estimate the thermal conductivity of a rock based on its classification on the Streckeisen diagram, a fact that may be of value for expeditious classification of rock samples used in civil engineering, for example. In particular, for igneous and ortho-derived rocks, the performances of the models based on just two phases (CM and MW-models) were quite reasonable. This result is in accordance with the well-known fact that the quartz content is the dominant factor in explaining the thermal conductivities of crystalline rocks. Because of the strong dependence on the quartz content, even estimates derived from the silica percent weight can satisfactorily account for conductivity variations of igneous rocks, a result that could be of value for gross estimates of thermal conductivity of rocks based on their fragments.

Departures from these general conclusions occur basically in two cases: the first one is when the rock conductivity is either too high or too low; the second case occurs when the rock is rich in platy-minerals, as schist for example. For both cases, it is necessary to take into account other factors besides the observed mineral content.

\section{ACKNOWLEDGEMENTS}

DTF thanks CAPES for the scholarship. WEM thanks CNPq for the research fellowship under grant 304301/2011-6. The research project "Parametrização de afloramentos do embasamento cristalino das Bacias do Ceará e interiores do trend Cariri-Potiguar 

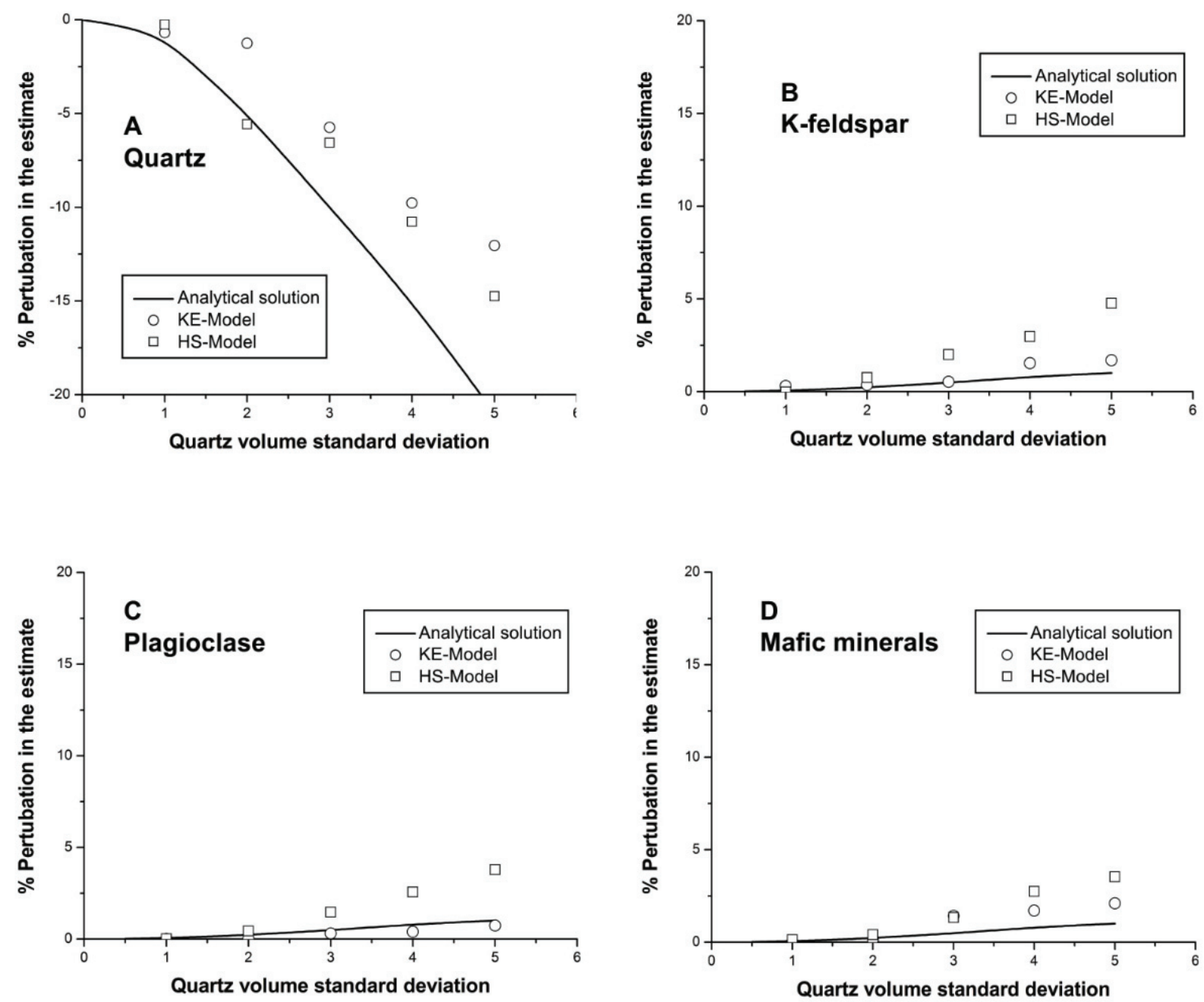

Figure 11 - Sensibility of the effective estimates of mineral conductivities obtained with the KE-model $\left(\ell_{2}\right.$ norm) due to perturbation on the quartz volume fraction for the igneous and ortho-derived rocks. Percent relative perturbations are calculated with respect the set of estimates shown in Table 3 . The solid black line is the analytical solution.

para estudos de condutividade térmica: um tema em continuidade (UFRN/PETROBRAS-CENPES/FUNPEC)" gave support for the laboratory and petrographic modal analyses. We also thank an anonymous reviewer for the careful revision of the first version of this manuscript.

\section{REFERENCES}

ALMEIDA FFM, HASUI Y, BRITO NEVES BB \& FUCK HA. 1981. Brazilian structural provinces: An introduction. Earth-Science Reviews, 17: 1-29.

ANDERSSON J, STROM A, SVEMAR C, ALMEN K-E \& ERICSSON LO. 2000. What requirements does the KSB-3 repository make on the host rock? Geoscientific Suitability Indicators and Criteria for Siting and Site Evaluation. Technical Report, TR-00-12.
BRITO NEVES BB \& CORDANI UG. 1991. Tectonic evolution of South America during the Late Proterozoic. Precambrian Research, 53: 23-40.

BUNTEBARTH G \& SCHOPPER JR. 1998. Experimental and theoretical investigations on the influence of fluids, solids and interactions between them on thermal properties of porous rocks. Phys. Chem. Earth, 23: 1141-1146.

CARSLAW HS \& JAEGER JC. 1959. Conduction of Heat in Solids. Oxford University Press. $520 \mathrm{pp}$.

CHAPMAN DS. 1986. Thermal gradients in the continental crust. Geol. Soc. Spec. Publ., 24: 63-70.

CHAYES F. 1956. Petrographic Modal Analysis. John Wiley \& Sons. $139 \mathrm{pp}$.

CLAUSER C \& HUENGES E. 1995. Thermal Conductivity of Rocks and 

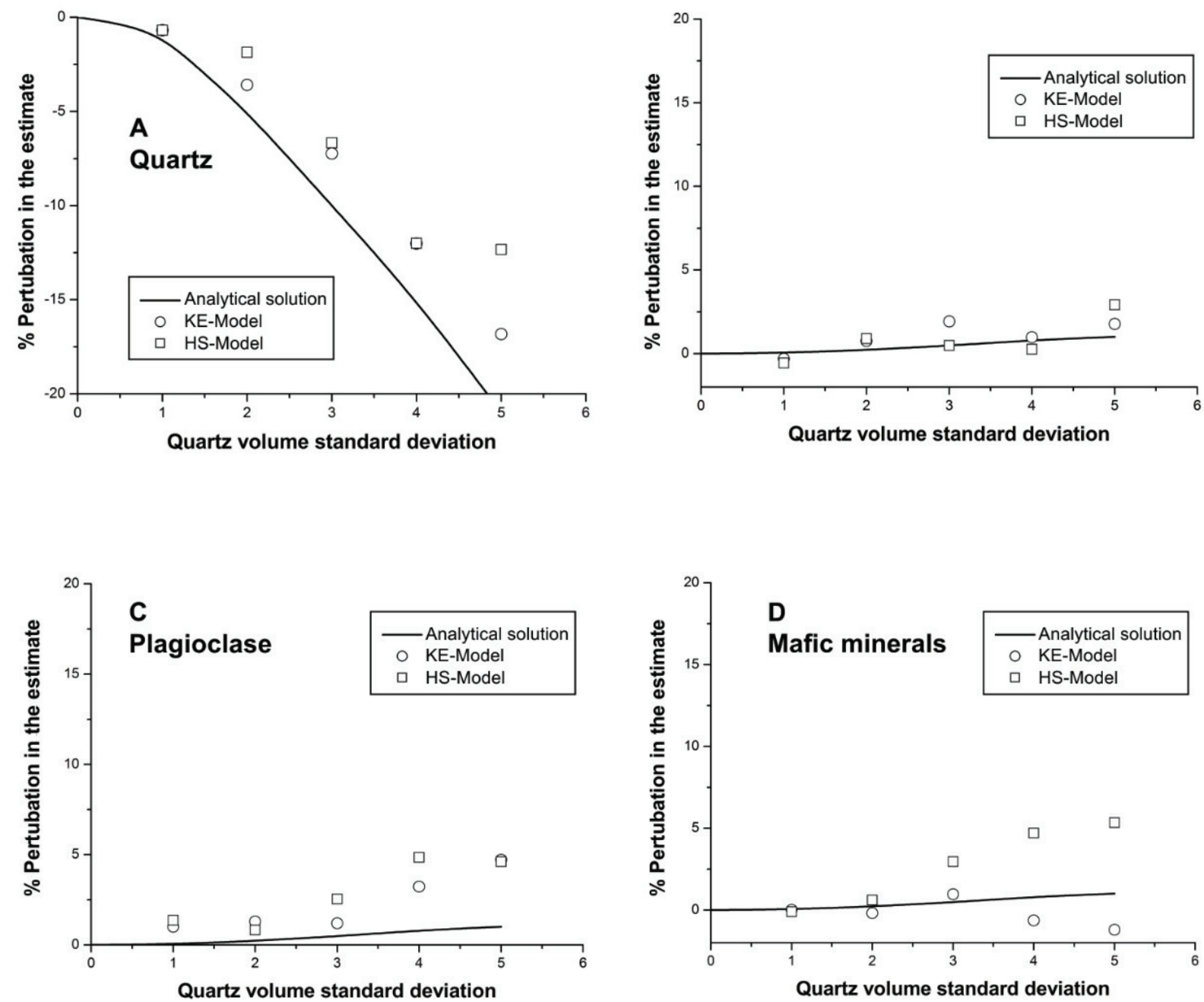

Figure 12 - Sensibility of the effective estimates of mineral conductivities obtained with the KE-model $\left(\ell_{2}\right.$ norm) due to perturbation on the quartz volume fraction for the metasedimentary rocks. Percent relative perturbations are calculated with respect the set of estimates shown in Table 3 . The solid black line is the analytical solution.

Minerals. AGU Handbook of Physical Constants. American Geophysical Union. Reference Shelf, 3: 105-126.

DI SIPIO E, CHIESA S, DESTROE, GALGAZO A, GIARETTA A, GOLA G \& MANZELLAA. 2013. Thermal conductivity as key parameter for geothermal numerical models. Energy Procedia, 40: 87-94.

FIGUEIREDO ERH. 2006. Condutividade térmica de rochas: uma aplicação para granitos ornamentais. Master Dissertation, Universidade Federal do Rio Grande do Norte, Natal, Brazil. 91 pp.

FIGUEIREDO ERH, GALINDO AC, LINS FPL \& MOREIRA JAM. 2009. Condutividade térmica em rochas silicáticas cristalinas e sua correlação com a geoquímica de elementos maiores. Estudos Geológicos, 19: 55-68.

GOMES AJL \& HAMZA VM. 2005. Geothermal gradient and heat flow in the State of Rio de Janeiro. Brazilian Journal of Geophysics, 23(4):
325-347.

HAMZA VM. 1982. Pesquisas de medições de temperatura subsuperficial: Importância para a hidrogeologia. Revista de Águas Subterrâneas, 5: 65-99.

HASHIN Z \& SHTRIKMAN S. 1962. A variational approach to the theory of the effective magnetic permeability of multiphase materials. J. Appl. Phys., 33: 3125-3131.

JESSOP AM. 1983. The essential ingredients of a continental heat flow determination. Zbl. Geol. Paläontol., 1: 70-79.

JESSOP AM. 2009. Models of thermal conductivity of crystalline rocks. Int. J. Earth Sci. (Geol. Rundsch), 97: 413-419.

MENKE W. 1984. Geophysical Data Analysis: Discrete Inverse Theory. Academic Press. 260 pp. 
OLIVEIRA RG. 2008. Arcabouço geofísico, isostasia e causas do magmatismo Cenozóico da Província Borborema e de sua margem continental (Nordeste do Brasil). Doctorate Thesis, Universidade Federal do Rio Grande do Norte, Natal, Brazil. 411 pp.

PRESS WH, TEUKOLSKY SA, VETTERLING WT \& FLANNERY BP. 1996. Numerical recipes in Fortran 77: The Art of Scientific Computing. 2nd ed., Cambridge Univ. Press. 933 pp.

RICHARDSON JA \& KUESTER JL. 1973. The complex method for constrained optimization. Comm. ACM, 16: 487-489.

SANTANA FL, MEDEIROS WE, DO NASCIMENTO AF \& BEZERRA FHR. 2012. Hypocentral relocation using clustering-along-planes constraints - implications for fault geometry. Geophysical J. Int., 190: 1077-1090.

SANTOS EJ \& MEDEIROS VC. 1999. Constraints from granitic plutonism on proterozoic crustal growth of the Transverse Zone, Borborema Province, NE-Brazil. Revista Brasileira de Geociências, 29: 73-84.
SCHÖN JH. 2004. Physical Properties of Rocks: Fundamentals and Principles of Petrophysics. Seismic Exploration, vol. 18. Elsevier. 583 pp.

SILVA TJO. 2016. Propriedades físicas de rochas versus tipologias de granitoides Ediacaranos no domínio Rio Grande do Norte, porção Nordeste da Província Borborema. Master Dissertation, Universidade Federal do Rio Grande do Norte, Natal, Brazil. 45 pp.

STRECKEISEN A. 1976. To each plutonic rock its proper name. Earth Sci. Rev., 12: 1-33.

TIKHONOV AN \& ARSENIN VY. 1977. Solutions of III-Posed Problems, John Wiley \& Sons. 258 pp.

TROMPETTE R. 1994. Geology of Western Gondwana (2000-500 Ma): Pan-African-Brasiliano Aggregation of South America and Africa. A.A. Balkema, Rotterdam, Brookfield, 350 pp.

Recebido em 30 novembro, 2015 / Aceito em 13 julho, 2017

Received on November 30, 2015 / Accepted on July 13, 2017 